\title{
Role of Graded Compression Ultrasonography in Evaluation of Acute Appendicitis.
}

\author{
Mukunda Singh Shrestha ${ }^{1}$, Hom Prasad Pant ${ }^{2}$, Shiv Bahadur Basnet ${ }^{l}$, Govinda Bhahadur khadka ${ }^{1}$ \\ Rajive Raj Shahil, Sujata Pantal. \\ ${ }^{1}$ Department of Radiodiagnosis, Shree Birendra Hospital, Kathmandu, Nepal. \\ ${ }^{2}$ Resident, National Academy of Medical Sciences.
}

\begin{abstract}
Introduction: Acute appendicitis is common surgical emergency which can lead to high morbidity and mortality in absence of timely treatment. Ultrasonography (USG) is commonly used to diagnose appendicitis and exclude other intraabdominal pathology leading to right iliac fossa pain in emergency setting. We aimed to find out the diagnostic value of graded compression USG in suspected appendicitis cases.

Methods: Altogether 107 patients with clinical impression of acute appendicitis were followed. Four cases were excluded because of other diagnosis established in USG. Appendicitis was diagnosed by standard criterias of inflammed appendix by graded compression technique. Informations of 103 cases were recorded in proforma which was later entered in SPSS and statistical calculations done.

Results: Out of 103 cases followed, 93 had appendicitis. Of those, 46 cases only showed inflammed and distended appendix, others showed ancillary features only. Males were more affected 61(65.6\%) than females. Sensitivity, specificity, positive predictive value, negative predictive value and accuracy of ultrasound in detecting appendicitis were $98.9 \%, 90 \%, 98.9 \%, 90 \%$ and $97.1 \%$ respectively.
\end{abstract}

Conclusions: Graded compression ultrasonography is good investigation modality in assessement of suspected acute appendicitis.

Keywords: appendicitis; graded compression ulrasonography; laparotomy.

\section{INTRODUCTION}

Acute appendicitis is one of the commonnest surgical emergency presenting clinically with right lower quadrant abdominal pain, nausea and fever. Making the decision for a surgical operation based only on the patient's signs and symptoms results in removing normal appendices (negative appendectomy) in 15\% to $30 \%$ of cases $^{1-2}$, and delay in diagnosis due to clinical dilemma and extensive investigations can lead to perforation and peritonitis, which leads to high mortality and morbidity ${ }^{3}$.

Computerised tomography (CT) scanning has become the standard modality in the diagnosis of appendicitis in both children and adults but its liberal use has come under fire recently because of the risk of malignancy due to its ionizing radiation ${ }^{4}$, also the high cost of investigation and nonavailability in most emergency set up makes CT as no replacemnt for ultrasonography. Other methods like barium enema has less diagnostic accuracy ${ }^{5}$.

Graded compression ultrasonography (USG) is an inexpensive, fast and noninvasive method with an accuracy rate of $71 \%-90 \%$ for the diagnosis of acute appendicitis ${ }^{6}$. Still few cases are missed due to various reasons like obesity, severe guarding and excessive bowel gases ${ }^{7}$. Moreover, lack of proper infrastructure (poor quality ultrasound machine) and sufficient time to patient care can lead to less detection of appendicitis by ultrasound.

\section{Correspondence:}

Lt Col Dr Mukunda Singh Shreshta

Department of Radiology ( Shree Birendra Hospital)

Email : shrestha_mukunda@hotmail.com 
Our study aims to find out diagnostic yield of graded compression USG in identifying appendicitis correctly and to find out the cause for negative ultrasound in imaging.

\section{METHODS}

Retrospective hospital based study was conducted at Shree Birendra Hospital. Altogether, 107 patients with clinical impression of acute appendicitis with datailed medical records were followed from April 2012 to March 2013. Patients with peritoneal abscess, abdominal tuberculosis, GI malignancy were excluded.

Clinical assessment was done by experienced surgeon. Patient presenting with right lower quadrant pain, nausea/vomiting, decreased appetite, guarding and tenderness of right iliac fossa were clinically suspected as acute appendicitis. Ultrasound was carried out in Medison aqua 300 machine by experienced radiologists. Linear transducer with frequency of 7.5$10 \mathrm{Mhz}$ was used and graded compression was used while looking for appendix. B mode and color doppler were also used.

Using ultrasound, patients were classified in 3 groups: definite appendicitis, suggestive of appendicitis and negative appendicitis. Ultrasound diagnosis of appendicitis was done by blind ending non compressible tube originating from base of cecum with diameter $6 \mathrm{~mm}$ or more with bowel (target) sign (figure 1). Appendicolith was also taken as surest sign of appendicitis. Likely appendicitis was defined for cases whose appendix was not visualised but if there are features of mesenteric inflammation like increased pericecal mesenteric vascularity, minimal interbowel fluid collection and rebound tenderness seen in right iliac fossa region. At least three of those features had to be present to call it as likely acute appendicitis. Negative appendicitis was defined by cases where appendix was seen but not inflammed (compressible and smaller than $5 \mathrm{~mm}$ in diameter) or appendix not seen and no features of periappendiceal inflammation noted in both B mode and color doppler study. Perforated appendix was defined by swollen/inflammed appendix with free fluid collection in RIF or when direct wall defect was noted or when appendicolith was noted in peritoneal cavity. Subacute bowel obstruction was defined by dilated bowel loops in setting of vomiting in those patients. In those cases, where laparotomy was not done after negative ultrasound scan, were followed by medical records for 3 months, and where no medical record was present, patient were followed up by phone calls directly to look for features of appendicitis/ treatment elsewhere. Histopathological confirmation was followed in most cases.

Data was entered in preformed proforma which was later entered in statistical programme for social science (SPSS) version 16 and analysed. Sensitivity, Specificity, Positive predictive value (PPV), Negative predictive value (NPP) and accuracy of sonographic evaluation was calculated from standard formula. Numerically significant variables were subjected for chi square tests and correlation analysis, and statistically significant were defined by $p$ value less than 0.05 .

\section{Figure 1: acute appendicitis in ultrasound image}
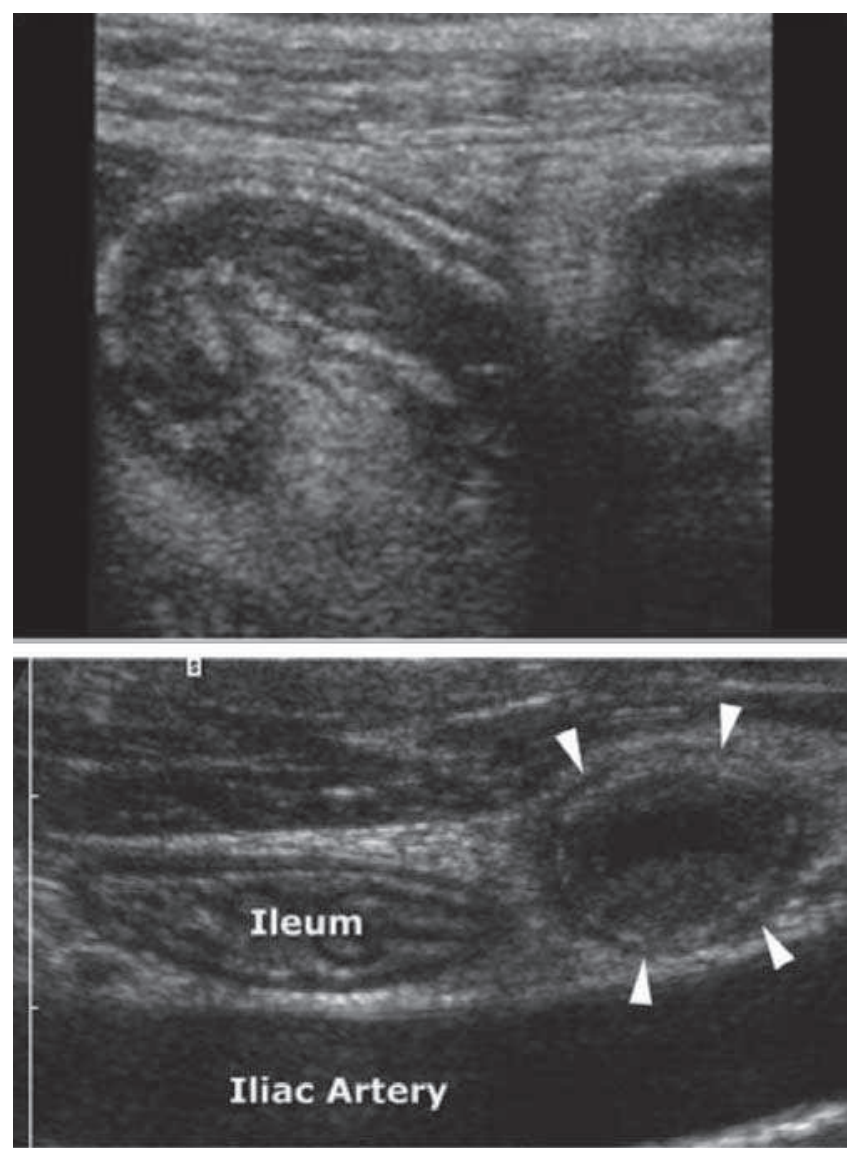

\section{RESULTS}

Of 107 cases undergoing ultrasonography for suspected appendicitis, three cases were found to have ovarian cyst and one case was found to have hydronephrosis with renal calculi, remaining 103 cases were enrolled in our study. Among these 103 cases, 93 showed appendicitis; 61 (65.6\%) males and 32 (33.4\%) females (figure 2). Mean age of presentation was $28.87 \pm 12.18$ year. Most of the patient (75\%) visited hospital within 2 days, $37 \%$ within first day itself (table 1). Definite inflammed appendix was seen in 46 cases 
MJSBH July-December 2013|Vol 12| Issue 2

(49.4\% of appendicitis patients). Fourty eight (46.6\%) cases showed features of inflammation of appendix but appendix was not visible, which were categorised as likely appendicitis cases. Negative appendicitis was diagnosed in 10 cases in ultrasound. In follow up of these patients, one developed features like appendicitis requiring laparotomy.

Mean diameter of appendix was $8.8 \pm 2.2 \mathrm{~mm}$,with mean thickness of wall $3.2 \mathrm{~mm}$ (ranging from 2-4mm). Appendicolith was noted in 7 cases $(6.8 \%)$ only. Complication overall in USG was noted in 6 cases, of those 4 had perforation and 4 had sub acute Intestinal obstruction; two patient with perforation also had sub acute Intestinal obstruction.

Of total 103 cases, 93 underwent laparotomy. Out of these, 92 cases showed features of appendicitis and 1 showed normal appendix. These all were ultrasound positive cases. Perforation as complication were mentioned in 4 cases who had documentation in USG also. Sensitivity, specificity, PPV, NPV and accuracy of ultrasound in detecting appendicitis was 98.9\%, $90 \%, 98.9 \%, 90 \%$ and $97.1 \%$ respectively(table 2 ).

Figure 2: Appendicitis in males and females

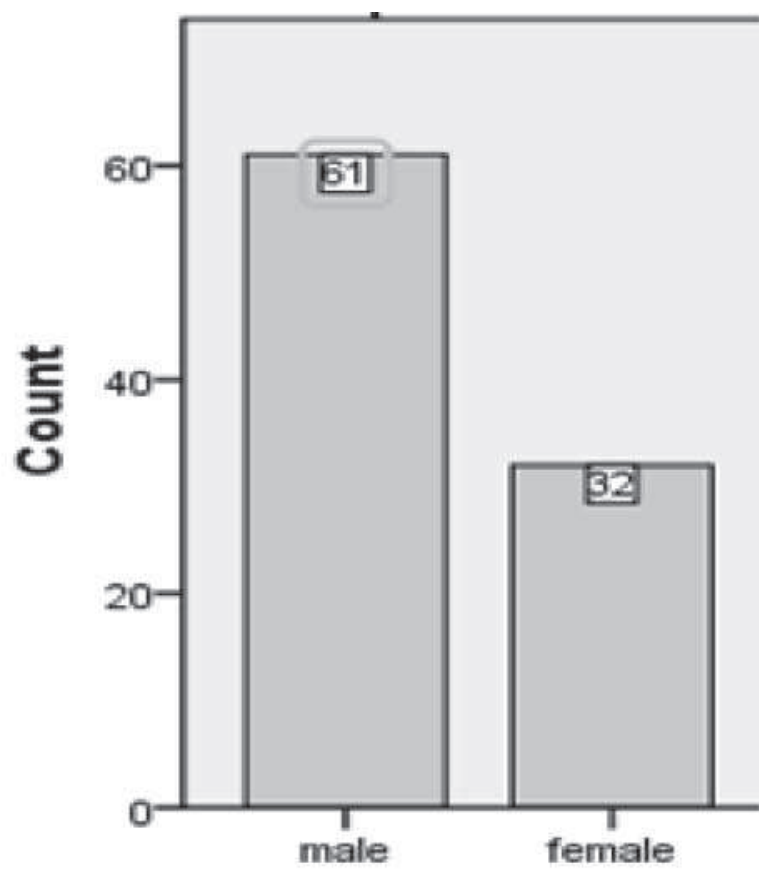

gender

Table 1: Mean value of descriptive variables

\begin{tabular}{|l|l|l|}
\hline Variables & Mean & Range \\
\hline Age & $\begin{array}{l}28.87(\mathrm{SD}=12.17) \\
\mathrm{yr}\end{array}$ & $10-70$ \\
\hline
\end{tabular}

\begin{tabular}{|l|l|l|}
\hline $\begin{array}{l}\text { Duration of pain } \\
\text { in days }\end{array}$ & $\begin{array}{l}2.14(\mathrm{SD}=1.52) \\
\text { days }\end{array}$ & $1-12$ \\
\hline $\begin{array}{l}\text { Diameter of } \\
\text { appendix }\end{array}$ & $8.8(\mathrm{SD}=2.24) \mathrm{mm}$ & $6-15$ \\
\hline $\begin{array}{l}\text { Thickness of } \\
\text { wall }\end{array}$ & $3.22(0.69) \mathrm{mm}$ & $2-4$ \\
\hline
\end{tabular}

Table 2: Sensitivity, Specificity, PPP, NPV, accuracy of USG

\begin{tabular}{|l|l|}
\hline Parameters & Value in percentage \\
\hline Sensitivity & $98.9 \%$ \\
\hline Specificity & $90 \%$ \\
\hline $\begin{array}{l}\text { Positive predictive } \\
\text { value }\end{array}$ & $98.9 \%$ \\
\hline $\begin{array}{l}\text { Negative predictive } \\
\text { value }\end{array}$ & $90 \%$ \\
\hline Accuracy & $97.1 \%$ \\
\hline
\end{tabular}

\section{DISCUSSSION}

Acute appendicitis is the most common abdominal surgical emergency with lots of difficulty in diagnosis. There is great variation in performance in diagnosing appendicitis by ultrasound. Mean age of presentation was 28.87 year and is comparable to Khanal $\mathrm{Br}$ et al findings 8 . In USA, male have higher incidence of apendicitis ${ }^{9}$. Our study also showed more males suffer from appendicitis compared to females, aggreing previous findings of study conducted in Nepal by Khanal BR et $\mathrm{al}^{8}$. Mean time of presentation to hospital was early, $75 \%$ presenated within first 2 days of pain,this explains less complication rate like perforation in our study in contrary to higher complication rate in some studies ${ }^{10,11}$. Perforation is found to be higher in males than in females (actually,all were male) which is supporting earlier findings ${ }^{11}$. Perforation is found to be high in young children, toddler, extremes of age and delayed presentation ${ }^{11-13}$. Young children cannnot communicate well and they have less protective omental fat, which leads to more perforation ${ }^{11-13}$. Females overall had other intraabdominal pathologies erroneously suspected as acute appendicitis which is common due to multiple gynaecological problem mimicking acute appendicitis ${ }^{11}$. Overall complication detection rate in USG was very good.

Ultrasonographic diagnosis of appendicitis has high sensitivity, specificity and accuaracy. It was compatarable to previous many literatures including previous study from Nepal ${ }^{1-3,8,14}$. Negative predictive value of $90 \%$ in our study is much higher than reported in some literatures ${ }^{8}$, but is parallel to that of other 
study ${ }^{14}$. Sonography may miss perforated, retrocecal appendix and appendix in elderly ${ }^{7,15}$. Missing direct visualisation of many of the appendix in our study may be because of lack of direct compression of back of lumbar region by hand and not seeing patient in left lateral position. Appendix of children are easily visible due to less fat in abdomeninal musculature ${ }^{16}$, most of our cases were not children, that may have led to decreased direct visualisation of appendix. But overall reporting of appendicitis cases as ultrasonologcally appendicitis was good. This signifies correlation with clinical and laboratory findings of those cases is very important,as mesenteric inflammation in right iliac fossa may occur due to variety of causes. Sensitivity of CT is better than ultrasound because of multiple reasons like fat in omentum and is not operator dependant but specificity parallels ${ }^{10,17}$. But again, CT is not cost effective, easily accessible and has high radiation. CT can be used in doubtful cases after USG screening ${ }^{17,18}$. MRI has role in diagnosis of suspected appendicitis in pregnanat as USG detection is low and there is radiation risk with CT scan ${ }^{19}$.

Main limitation of our study was a retrospective methodology and diagnostic value of clinical impression could not be evaluated as all cases with right iliac fossa pain didn't undergo appendicitis but only those suspected by surgeons were sent for USG.

\section{CONCLUSION}

Graded compression ultrasonography is $97.1 \%$ accurate in diagnosing acute appendicitis with $98.8 \%$ sensitivity and $90 \%$ specificity.

\section{REFERNCES}

1. Chan I, Bicknell SG, Graham M: Utility and diagnostic accuracy of sonography in detecting appendicitis in a community hospital. AJR Am J Roentgenol 2005, 184(6):1809-1812. http:// dx.doi.org/10.2214/ajr.184.6.01841809.

2. Gökçe AH, Aren A, Gökçe FS, Dursun N, Barut AY: Reliability of ultrasonography for diagnosing acute appendicitis. Ulus Travma Acil Cerrahi Derg 2011, 17(1):19-22. http://dx.doi.org/10.5505/ tjtes.2011.82195

3. Binnebösel M, Otto J, Stumpf M, Mahnken AH, Gassler N, Schumpelick V, Truong S: Acute appendicitis. Modern diagnostics-surgical ultrasound.Chirurg 2009, 80(7):579-587. http:// dx.doi.org/10.1007/s00104-009-1684-1

4. Brenner DJ, Hall EJ. Computed tomography - an increasing source of radiation exposure. N. Engl. J. Med. 2007;357(22):2277-84. http://dx.doi. org/10.1056/NEJMra072149

5. Balthazar EJ: Appendicitis: prospective evaluation with high-resolution CT.Radiology. 1991, 180:2124.

6. Puylaert JB, Rutgers PH, Lisang RI, et al. A prospective study of ultrasonography in the diagnosing of appendicits. $\mathrm{N}$ Engl $\mathrm{J}$ Med. 1987;317:666-9. NEJM198709103171103

7. Ang A, Chong NK, Daneman A. Pediatric appendicitis in "real-time": The value of sonography in diagnosis and treatment. Pediatr. Emerg. Care 2001;17(5):334-40.http://dx.doi. org/10.1097/00006565-200110000-00004. PMid:11673709

8. Khanal BR, Ansari MA, Pradhan S. Accuracy of ultrasonography in the diagnosis of acute appendicitis. Kathmandu University Medical Journal (2008);6(21):70-4.

9. Addis DG, Shaffer N, Fowler BS, Tauxe RV. The epidemiology of appendicitis and appendectomy in the United States, Am j Epidemiol 1990;132:91025.

10. Karakas SP, Guelfguat M, Leonidas JC, Springer S, Singh SP. Acute appendicitis in children: comparison of clinical diagnosis with ultrasound and CT imaging. Pediatr Radiol. 2000 Feb;30(2):94-8. http://dx.doi.org/10.1007/ s002470050023 PMid:10663520

11. Andersson RE, Hugander A, Thulin AJ, 1992. Diagnostic accuracy and perforation rate in appendicitis: association with age and sex of the patient and with appendicectomy rate. Eur J Surg 158(1):37-41.

12. Hale DA, Molloy M, Pearl RH, et al. Appendectomy: a contemporary appraisal. Ann Surg 1997;225(3):252-61. http://dx.doi. org/10.1097/00000658-199703000-00003 PMid:9060580

13. Nelson DS, Bateman B, Bolte RG. Appendiceal perforation in children diagnosed in a pediatric emergency department. Pediatr Emerg Care 2000;16(4):233-7.http://dx.doi. org/10.1097/00006565-200008000-00004 PMid:10966339

14. Wade DS, Marrow SE, Balsara ZN, Burkhard 
TK, Goff WB. Accuracy of ultrasound in the diagnosis of acute appendicitis compared with the surgeon's clinical impression. Arch Surg. 1993 Sep;128(9):1039-44; discussion 1044-6. http://dx.doi.org/10.1001/ archsurg.1993.01420210103014 PMid:8368922

15. Ma OJ, Mateer J, Blavais M. Emergency Ultrasound. 2nd ed. 2007. McGraw Hill.

16. Josephson T, Styrud J, Eriksson S. Ultrasonography in acute appendicitis: Body mass index as selection factor for US examination. Acta. Radiol. 2000;41(5):486-8.http://dx.doi.org/10.1034/ j.1600-0455.2000.041005486.x PMid:11016772

17. Doria AS, Moineddin R, Kellenberger CJ, et al. US or CT for diagnosis of appendicitis in children and adults? A meta-analysis. Radiology 2006;241(1):83-94. http://dx.doi.org/10.1148/ radiol.2411050913. PMid:16928974

18. Poortman P, Oostvogel HJ, Bosma E, et al. Improving diagnosis of acute appendicitis: Results of a diagnostic pathway with standard use of ultrasonography followed by selective use of CT. J. Am. Coll. Surg. 2009;208(3):434-41. http:// dx.doi.org/10.1016/j.jamcollsurg.2008.12.003. PMid:19318006

19. Israel GM, Malguria $\mathrm{N}$, McCarthy $\mathrm{S}$, et al. MRI vs. ultrasound for suspected appendicitis during pregnancy. J. Magn. Reson. Imaging 2008;28(2):428-33. http://dx.doi.org/10.1002/ jmri.21456. PMid: 18666160 